\title{
Increase in age at onset of rheumatoid arthritis in Japan over a 30 year period
}

Toru Imanaka, Kanji Shichikawa, Koji Inoue, Yasunori Shimaoka, Yoshitaka Takenaka, Shigeyuki Wakitani

\begin{abstract}
Objectives-To determine changes in demographic variables and severity of rheumatoid arthritis (RA) that may have occurred during the 30 year period from 1960 to 1990 in Japan.

Methods-Using records of patients diagnosed with RA from two hospitals, demographic and clinical features at initial visit were compared between two groups, one from 1960 to 1965 (group I) and the other from 1985 to 1990 (group II). Results-Mean age at the time of onset of the disease increased significantly from 37.5 years in group I to 46.9 in group II. The peak age at onset of RA shifted from the third to the fifth decade between group I and group II. There was no obvious change in morbidity as determined by seropositivity, rheumatoid nodules, and assessments of hip involvement.

Conclusion-The age at onset of RA was delayed during a recent 30 year period in Japan. This increase in age at onset might result from environmental changes that occurred in Japan or may reflect a birth cohort phenomenon. Improvement of severity of disease was not found in this study.
\end{abstract}

Department of

Rheumatology,

Shichikawa Arthritis

Research Centre,

Hisai, Mie, Japan

T Imanaka

K Shichikawa

Y Takenaka

Department of

Orthopaedic Surgery,

Shiga University of

Medical Science, Otsu,

Japan

$\mathrm{K}$ Inoue

Department of

Orthopaedic Surgery,

Osaka University

Medical School,

Osaka, Japan

Y Shimaoka

Department of

Orthopaedic Surgery,

Osaka-Minami

National Hospital,

Kawachi-Nagano,

Japan

S Wakitani

Correspondence to:

Dr T Imanaka, Department of Orthopaedic Surgery,

Shiga University of Medica

Science, Seta

Tsukinowa-cho, Otsu, Shiga 520-21, Japan.

Accepted for publication 5 February 1997 pital from 1960 to 1965 (group I), and 366 patients (67 males, 299 females) who visited the Shichikawa Arthritis Research Centre between 1985 and 1990 (group II) were examined. The first hospital is located in an urban area and the second in a rural area. All patients were diagnosed as having definite or classic RA according to diagnostic criteria of the American Rheumatism Association. ${ }^{10}$ This study comprised records for all consecutive patients, who visited the hospital for the first time during those periods. At both institutes, one of the study's authors (K S) was working as the chief of rheumatologists for each chronological period studied, and the same data items could be obtained. Data were gathered and recorded for each patient upon the initial visit, including sex, age, disease duration, age at onset, seropositivity, presence of rheumatoid nodules, and hip involvement. Data for both groups were then compared.

Clinical examinations of both groups of patients were performed by experienced rheumatologists. Seventy nine per cent of patients in group I and $73 \%$ of those in group II were examined by one of the study's authors (K S). Statistical analysis was performed using the $\chi^{2}$ test and Student's $t$ test.

\section{Results}

Table 1 shows a basic comparison of clinical data between groups I and II. Group I consisted of 125 males and 441 females (total 566), and group II of 67 males and 299 females (total 366). The male to female ratio was 1:3.5 in group I and 1:4.5 in group II, with no significant difference. The mean age at initial visit was 42.6 years (range 7-96) in group I and 54.5 (range 11-82) in group II. This difference was statistically significant $(p<0.001)$. The mean duration of the disease was 4.9 years (range 0.5-44) in group I and 7.5 (range 0.5-40) in group II, showing statistical significance $(p<0.001)$. This significant difference in the mean disease duration was the case for female patients (4.9 years versus 8.1 years for group I and group II, respectively; $\mathrm{p}<0.001$ ), although there was no significant difference in male patients (4.9 years versus 4.8 years). The mean age at onset of 46.9 years (range 9-76) in group II was significantly higher compared with 37.5 (range 7-96) in group I $(p<0.001)$, and this was the case for both sexes ( 41.3 versus 54.0 for male patients and 36.5 versus 45.3 for female patients). There was no significant difference in seropositivity between the two groups $(69.5 \%$ versus $75.1 \%$ ), and this was the case regardless of the specific 10 year range of age at onset (data not shown). Similarly, percentages of patients with rheumatoid nodules in group I and group II (9.9\% versus $12.3 \%)$ and those 
Table 1 Comparison of clinical characteristics between groups I and II

\begin{tabular}{lll}
\hline & Group I & Group II \\
\hline Initial visit (year range) & $1960-1965$ & $1985-1990$ \\
Institution & Osaka University & Shichikawa Arthritis \\
& Hospital & Research Centre \\
Number of patients total & 566 & 366 \\
Male & 125 & 67 \\
Female & 441 & 299 \\
Ratio of males to females & $1: 3.5$ & $1: 4.5$ \\
Age at initial visit (y) : (mean (SD)) & $42.6(14.3)$ & $54.5(11.7)^{\star}$ \\
Disease duration (y) total : (mean (SD)) & $4.9(6.1)$ & $7.5(8.2)^{\star}$ \\
Male : (mean (SD)) & $4.9(6.8)$ & $4.8(4.5)$ \\
Female : (mean (SD)) & $4.9(5.9)$ & $8.1(8.7)^{\star}$ \\
Age at onset (y) total : (mean (SD)) & $37.5(14.1)$ & $46.9(13.9)^{\star}$ \\
Male : (mean (SD)) & $41.3(15.3)$ & $54.0(12.1)^{\star}$ \\
Female : (mean (SD)) & $36.5(13.6)$ & $45.3(13.8)^{\star}$ \\
Seropositivity (\%) & 69.5 & 75.1 \\
Rheumatoid nodule positivity (\%) & 9.9 & 12.3 \\
Rate of hip involvement (\%) & 14.9 & 16.0 \\
\end{tabular}

*Significant difference $(\mathrm{p}<0.001)$ was observed between these two groups.

with hip joint involvement $(14.9 \%$ versus $16.0 \%$ ) did not differ greatly.

To adjust for disease duration and compare patients with similar duration, each group was divided into three subgroups according to duration: less than five years (subgroup a), five years or more but less than 10 years (subgroup b), and 10 years or more (subgroup c).

Table 2 shows a comparison between the subgroups of group I and those of group II. With regard to the male to female ratio, statistical difference was observed only in subgroups c (1:3.8 in group I and $1: 9.5$ in group II; $\mathrm{p}<0.05)$. Higher mean age at initial visit was evident in each subgroup of group II (40.8 in subgroup Ia versus 55.0 in IIa, 43.0 in Ib versus 52.3 in IIb, and 48.4 in Ic versus 55.3 in IIc; $\mathrm{p}<0.05)$. There was no statistical difference in mean disease duration in any of the subgroups. Mean age at onset was significantly higher in group II within any subgroup (39.2 in Ia versus 53.1 in IIa, 36.6 in Ib versus 45.5 in IIb, and 32.9 in Ic versus 37.4 in IIc; $p<0.05$ respectively). There was no notable difference in seropositivity and rheumatoid nodule positivity in any subgroup, whereas the rate of hip involvement in group II was significantly lower in subgroup a $(15.4 \%$ in Ia versus $7.2 \%$ in IIa; $\mathrm{p}<0.05)$.

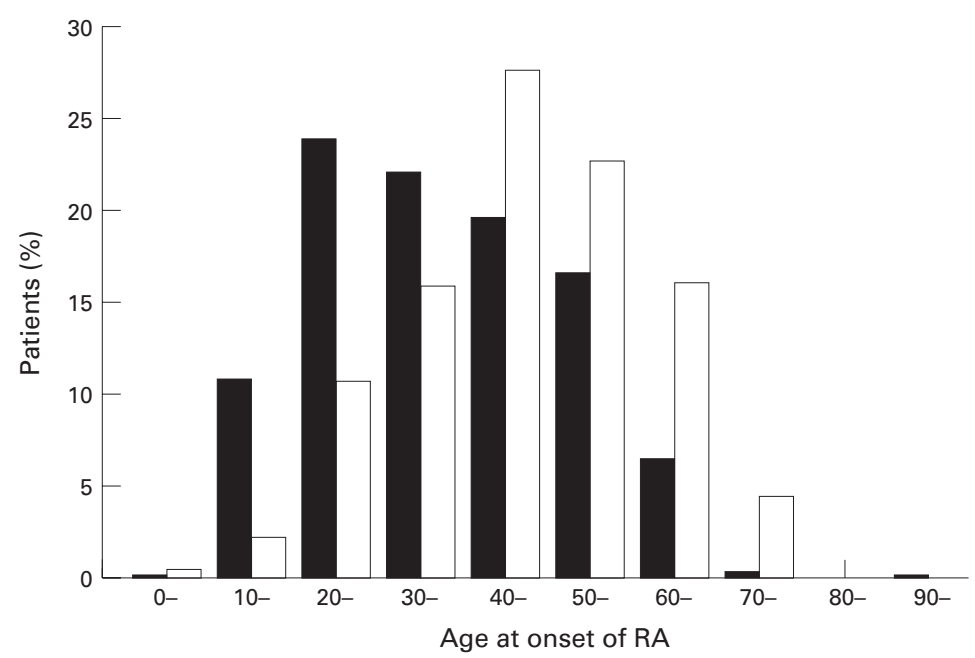

Figure 1 Distribution of age at onset. $\square$ : Group I patients who visited Osaka University Hospital from 1960 to 1965, $\square$ : group II patients who attended Shichikawa Arthritis Research Centre from 1985 to 1990.
Figure 1 shows the distribution of age at onset for groups I and II. A noticeable peak was observed in the 20 s in group I and in the 40 s in group II. Patterns of distribution of age at onset for female patients had a peak in the $20 \mathrm{~s}$ in group I and in the 40 s in group II, whereas for male patients the peak was in the 30 s and 50 s in group I and only in the 50s in group II. Similarly, the median age at onset was 36 in group I and 47 in group II. It was 35 for women in group I, 45 for women in group II, 41 for men in group I, and 53 for men in group II.

\section{Discussion}

Our study showed that the mean age at onset of group II patients was significantly higher than that of group I patients. A delay in the age at onset was a common feature of both men and women. This delay was still evident after adjusting for disease duration. Moreover, the peak age at onset shifted from the 20 s to the $40 \mathrm{~s}$. This shift was the same with regard to female patients, while in male patients the peak age at onset shifted from the 30 s and 50 s to only the 50s. The higher mean age at initial visit in group II can be attributed to the higher age at onset.

Because this study was a comparison of two groups of RA patients recruited in two units, 30 years apart, the possible biases involved in this kind of study should be examined. We considered some possibilities of a selection bias in the study. Firstly, Osaka University Hospital, the source of patient records for group I, is located in an urban area, whereas Shichikawa Arthritis Research Centre, the source for those in group II, is in a rural area. Consequently, there was a possibility that the hospital for group I selectively attracted younger patients, or that the population served by an urban hospital was younger than the population served by a rural hospital. However, analysis of 286 patients with RA making a first visit between 1985 and 1990 at Osaka University Hospital, the same hospital that our group I patients visited, showed a peak age at onset in the $40 \mathrm{~s}$ in both sexes, which correlates well with age at onset of the group II patients in this study (fig 2). For additional study, we obtained data from an urban hospital (Yukioka Hospital) where one of the authors (K S) has worked at an outpatient clinic, located near Osaka University Hospital, and other additional data from the Orthopaedic Department of Osaka-Minami National Hospital, situated in KawachiNagano city, on the outskirts of Osaka (table 3). Analysis of records of 233 patients with RA between 1985 and 1990 in the former, and of 370 patients between 1991 and 1994 in the latter, showed a corresponding peak age at onset in the $40 \mathrm{~s}$ with mean age at onset of 45.4 years and 44.8 years, respectively (fig 2 ).

These data showed a close resemblance with those of our group II patients, and the distribution pattern of age at onset of RA was the same, regardless of referral hospitals. Furthermore, Nobunaga has described the same phenomenon in Japanese literature ${ }^{11}$; specifically, mean age at onset of patients admitted with RA at the Department of Inter- 
Table 2 Comparison of data from two sources for patients with similar disease duration

\begin{tabular}{|c|c|c|c|c|c|c|}
\hline Disease duration & \multicolumn{2}{|l|}{$<5$ years } & \multicolumn{2}{|l|}{$\geq 5<10$ years } & \multicolumn{2}{|l|}{$\geq 10$ years } \\
\hline Subgroup & \multicolumn{2}{|c|}{ a } & \multicolumn{2}{|l|}{$\mathrm{b}$} & \multicolumn{2}{|l|}{ c } \\
\hline Group & I & II & $\bar{I}$ & II & I & II \\
\hline Number of patients & 353 & 178 & 112 & 83 & 101 & 105 \\
\hline Ratio of males to females & $1: 3.4$ & $1: 3.8$ & $1: 3.9$ & $1: 3.2$ & $1: 3.8$ & $1: 9.5^{\star}$ \\
\hline Age at initial visit (y) (mean (SD)) & $40.8(14.8)$ & $55.0(12.1)^{\star}$ & $43.0(13.7)$ & $52.3(12.3)^{\star}$ & $48.4(11.3)$ & $55.3(9.9)^{\star}$ \\
\hline Disease duration (y) (mean (SD)) & $1.4(1.3)$ & $1.6(1.4)$ & $6.8(1.3)$ & $6.3(1.3)$ & $15.5(6.5)$ & $18.0(7.8)$ \\
\hline Age at onset (y) (mean (SD)) & $39.2(14.6)$ & $53.1(12.3)^{\star}$ & $36.6(13.8)$ & $45.5(12.5)^{\star}$ & $32.9(11.6)$ & $37.4(11.9)^{\star}$ \\
\hline Seropositivity (\%) & 70.4 & 72.4 & 64.5 & 76.3 & 72.8 & 79.4 \\
\hline Rheumatoid nodule positivity (\%) & 8.5 & 12.0 & 9.8 & 12.0 & 15.1 & 13.5 \\
\hline Rate of hip involvement (\%) & 15.4 & $7.2^{\star}$ & 14.0 & 21.4 & 18.8 & 25.8 \\
\hline \multicolumn{7}{|c|}{ ॠSignificant difference $(\mathrm{p}<0.05)$ was observed between subgroups. } \\
\hline \multicolumn{7}{|c|}{ Table 3 Comparison of data from five sources for consecutive patients with $R A$} \\
\hline Institution & Period & City & Area & Patients (n) & $\begin{array}{l}\text { Peak age at } \\
\text { onset }\end{array}$ & $\begin{array}{l}\text { Mean disease } \\
\text { duration }(y)\end{array}$ \\
\hline \multicolumn{7}{|l|}{ Group I; Osaka University Hospital (Dept } \\
\hline Orthop Surg) & $1960-1965$ & Osaka & urban & 566 & $20 \mathrm{~s}$ & 4.9 \\
\hline \multicolumn{7}{|l|}{ Group II; Shichikawa Arthritis Research Centre } \\
\hline (Dept Rheumatol) & $1985-1990$ & Hisai & rural & 366 & $40 \mathrm{~s}$ & 7.5 \\
\hline Osaka University Hospital (Dept Orthop Surg) & 1985-1990 & Osaka & urban & 286 & $40 \mathrm{~s}$ & 5.7 \\
\hline \multirow{2}{*}{\multicolumn{2}{|c|}{$\begin{array}{l}\text { Yukioka Hospital (Dept Rheumatol) } \\
\text { Osaka-Minami National Hospital (Dept Orthop }\end{array}$}} & Osaka & urban & 233 & $40 \mathrm{~s}$ & - \\
\hline & & Kawachi- & & & & \\
\hline Surg) & 1991-1994 & Nagano & suburban & 370 & $40 \mathrm{~s}$ & 11.6 \\
\hline
\end{tabular}

nal Medicine, Medical Institute of Bioregulation, Kyushu University was 37.3 years between 1950 and 1960, 40.5 between 1966 and 1971 , and 44.1 between 1978 and 1983 .

Secondly, the possibility of selection bias because of the significant difference of disease duration should be considered. The mean duration of the disease was 4.9 years in group I and 7.5 years in group II. We therefore obtained the data concerning disease duration of patients making a first visit at either of the two hospitals, Osaka University Hospital between 1985 and 1990 and Osaka-Minami National Hospital between 1991 and 1994. As table 3 shows, disease duration was 5.7 and 11.6 years, respectively. Despite the varied length of mean disease duration, the peak age at onset was essentially similar between these hospitals.

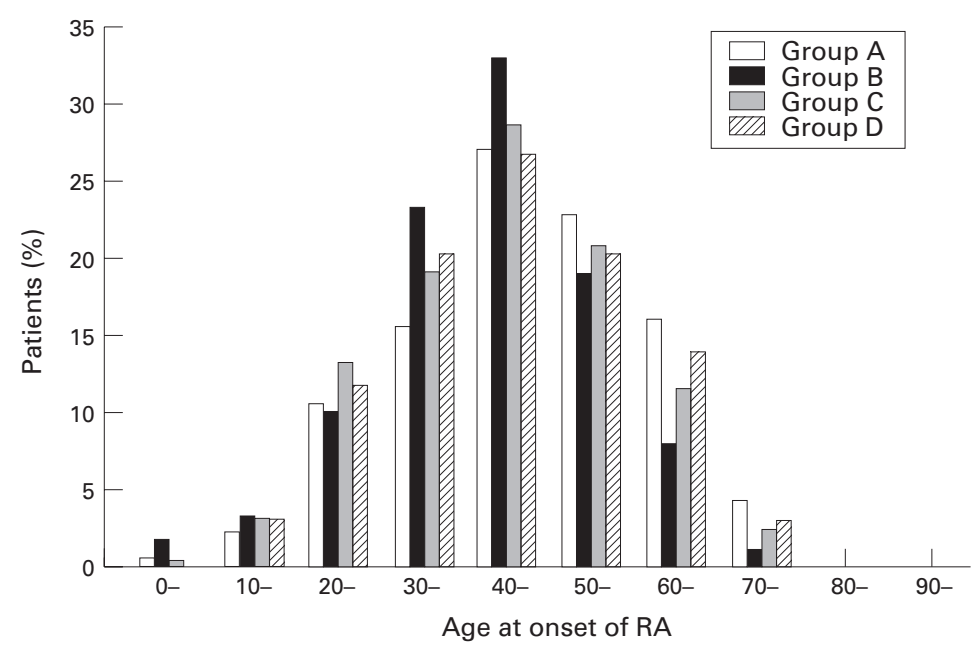

Figure 2 Distribution of age at onset. Group A: 366 patients at Shichikawa Arthritis Research Centre between 1985 and 1990, Group B: 286 patients at Osaka University Hospital between 1985 and 1990, Group C: 233 patients at Yukioka Hospital between 1985 and 1990, Group D: 370 patients at Osaka-Minami National Hospital between 1991 and 1994.
Thirdly, the relative increase of higher age at onset of RA may result from the increase in the average life span of the Japanese population in general. According to Japanese population statistics, the percentage of the population in their 20s was $17.7 \%$ in 1960 and $13.3 \%$ in 1985 , whereas for those in their $40 \mathrm{~s}$ it was $10.5 \%$ in 1960 and $14.3 \%$ in $1985 .^{12}$ These differences would not explain the considerable difference in distribution age at onset between two groups. Thus a delay in the age at onset seems to be a definite trend in Japan.

Numerous other demographic and environmental changes occurred in Japan during these years, such as increased female employment, reduction in the number of women having children, marrying later in life (especially in the case of women), amelioration of pollution in the environment, and reduction of microbiological infections. Although the effect of environmental changes on delay of age at onset of RA is beyond the scope of this study, some observable changes of this kind can be related to this delay.

The increased age at onset might reflect a birth cohort phenomenon. However, in any one time period, age at onset and year of birth are perfectly confounded, and in the comparison of two cross sectional surveys, such a hypothesis is impossible to test.

A significantly higher number of females was observed in group II when patients with long disease duration ( $\geq 10$ years) were compared. These results showed that there is an increasing tendency for women with RA to be referred to a major hospital at a late stage in the disease. Although we cannot identify the reason for this phenomenon, one possible explanation is increased employment rates for women and a shift away from extended families living together, which in the past enabled grandparents to take care of children and household duties when necessary. As a result of such changes, women have greater constraints 
upon their time, making it more difficult for them to visit a major hospital.

A decline in the severity of RA has been pointed out in Europe and Australia. ${ }^{157-913}$ This decline, indicated by seropositivity, radiographic erosions, and rheumatoid nodule positivity has been described by Silman et al..$^{57-9} \mathrm{~A}$ decline in radiographic severity has also been noted by Heikkilä et al. ${ }^{1}$ Because, in our study, the patients in group II have a longer disease duration, it could be reasonably assumed that more severe and more patients with longstanding disease were recruited for group II. However, a comparison of data, based on patients with similar disease duration, did not show any significant change over a 30 year period in seropositivity, rheumatoid nodule positivity, and rate of hip involvement, although a decreased rate of hip involvement was observed in group II patients with a disease duration of less than five years.

With regard to the severity of RA, a decrease during the last 30 years was not evident in this limited study. To answer definitely the question of whether the severity of RA has been declining in the Japanese population, it will be necessary to gather and compare additional data in a more extensive, systematic, epidemiological study.
1 Heikkilä S, Isomäki H. Long-term outcome of rheumatoid arthritis has improved. Scand J Rheumatol 1994;23:13-5.

2 Hochberg MC. Changes in the incidence and prevalence of rheumatoid arthritis in England and Wales: 1970-1982. Semin Arthritis Rheum 1990;19:294-302.

3 Jacobsson LTH, Hanson RL, Knowler WC, et al. Decreasing incidence and prevalence of rheumatoid arthritis in Pima Indians over a twenty-five-year period. Arthritis Rheum 1994;37:1158-65.

4 Linos A, Worthington JW, O'Fallon WM, Kurland LT. The epidemiology of rheumatoid arthritis in Rochester, Minnesota: a study of incidence, prevalence and mortality. Am J Epidemiol 1980;111:87-98.

5 Silman A, Davies P, Currey HLF, Evans SJW. Is rheumatoid arthritis becoming less severe? J Chron Dis 1983; 36:891-7.

6 Silman AJ. Has the incidence of rheumatoid arthritis declined in the United Kingdom? $\mathrm{Br} \mathrm{J}$ Rheumatol 1988;27:77-9.

7 Silman AJ. Are there secular trends in the occurrence and severity of rheumatoid arthritis? Scand J Rheumatol 1989; (suppl 79):25-30.

8 Silman AJ. Recent trends in rheumatoid arthritis (letter). $\mathrm{Br}$ J Rheumatol 1992;31:326-30.

9 Silman AJ. Trends in the incidence and severity of rheumatoid arthritis. J Rheumatol 1992; (suppl 32)19:71-3.

10 Popes MW, Bennett GA, Cobb S, Jacox R, Jessar RA. 1958 revision of diagnostic criteria for rheumatoid arthritis. Bull Rheum Dis 1958;9:175-6.

11 Nobunaga $M$. Does the therapy of RA really progress? Ryumachi 1986;26:35-40.

12 Statistics Bureau, Management and Coordination Agency. Population by age group and indexes of age structure (1920-1989). Japan Statistical Association, 1990; Printing Bureau, Ministry of Finance publication no. (ISBN)4620-80010-4. (Japan Statistical Yearbook, 40th ed).

13 Laurent R, Robinson RG, Beller EM, Buchanun WW. Incidence and severity of rheumatoid arthritis - the view from Australasia (letter). Br J Rheumatol 1989;28:360-1. 